\title{
The 400th anniversary of the birth of William Harvey
}

\author{
CHARLES NEWMAN ${ }^{1}$
}

William Harvey's discovery of the circulation of the blood is possibly the most famous of all scientific discoveries, and the fourth centenary of the birth of its author is as important as any centenary celebrations. We now can celebrate the wonderful advances in physiology, medicine, and surgery which have developed from it, but it must be remembered that for two hundred years it made no difference to any of these fields of activity. And yet, it was appreciated that it had been of profound importance. What it did at the time was this: it gave an actual, comprehensible demonstration of the scientific method of collecting observations, framing a provisional hypothesis to explain them, and testing the hypothesis by experiment. This scientific attitude has always been largely attributed to Francis Bacon, but wrongly: what he propounded was the collection of information on a large scale, and the consideration of it by a group of 'Interpreters', who just sat and thought. Bacon's idea of an experiment was one which answered the question: 'I wonder what would happen if ... ?' not whether it would confirm or disprove a hypothesis. But Harvey had clearly in mind, acted on, and described the modern method of scientific inquiry, and it was the direct effect of the 'De Motu Cordis' which stimulated the group of research workers in the College of Physicians, headed by Glisson, which was one of the formative influences in what became the Royal Society. It was such a transparently successful piece of work, so obviously imitable, that its effect can hardly be exaggerated. Moreover, it was widely disseminated, and became generally known in the 1620 's, and in his own lifetime Harvey had the satisfaction of knowing that it had been generally accepted, except in France, where English work has never been popular. There were two subsidiary aspects of Harvey's method which had great influence: it was the first physiological experiment which employed numerical proofs, it finally demolished the mediaeval beliefs that the

${ }^{1}$ Royal College of Physicians, 11 St. Andrew's Place, Regents Park, London NW1. arteries contained spirits, not blood, and that there were pores in the septum of the heart which allowed blood to pass between the ventricles; and it was the first scientific theory which was applied to clinical medicine, when Harvey explained a metastatic abscess in the brain from a pulmonary focus by suggesting circulatory transfer. That was the bcginning of clinical science, as Professor Booth has pointed out.

Almost exactly a hundred years later Stephen Hales did the first and only experiments for two hundred years on the circulation by measuring blood pressure in a mare, and calculating the output of the heart and the peripheral resistance of the small vessels, though nothing further developed from this except the important conclusion that the force of the arterial pressure could not explain muscular contraction.

What held up the application of Harvey's work to medicine was the failure to explain the function of respiration. From remote antiquity man had understood that the beating of the heart was intimately associated with the continuance of life, and that respiration was equally important. There had also been a feeling that the two were in some way connected, though as late as 1666 the thing that pleased Pepys most in a discourse with Sir George Ent about respiration was 'that it is to this day not known for what use it is' (Diary, 22 June 1666). It may be said that Harvey ought to have gone on to make observations on the pulse rate (though when Sir John Floyer did this in 1707, it led to very little), and that he might have observed oedema and cyanosis as associated with heart disease, but when one considers the difficulty over cardiac and pulmonary causes of cyanosis, and the confusion of renal and cardiac oedema, it would have been expecting a great deal even of Harvey.

The trouble lay fundamentally in the confusion about 'nitro-aerial particles', even in Harvey's lifetime. The first appearance of this seminal theory is often supposed to be Sir Kenelm Digby's speculation that the air contained particles related to saltpetre, which were responsible for the life of 
both plants and animals, particles which were picked up by plants somehow (he thought by mutual magnetic properties), from the air, not from water or the earth, which he argued convincingly at Gresham College in 1660, and published in 'The Vegetation of Plants'. He said he got the notion from 'The Cosmopolite', who turns out to have been a Pole called Michael Senziwoj, more pronouncably known as Sendivogius, who had been given it in a book, which he published as his own, at least as early as 1624 . The book was by a Scottish alchemist called Alexander Seton, whom Sendivogius had rescued from prison and torture in Dresden; Seton had the advantage of appearing to be able in fact to transmute base metal into gold. He died in 1604. The mistake, and it was a fatal one, which Seton, Digby, and their successors made was to suppose, naturally, that the nitro-aerial particles, 'the hidden food in the air', were the same for both plants and animals, thereby confusing what was really oxygen with carbon dioxide. Van Helmont had isolated carbon dioxide and called it 'gas sylvestre' in Harvey's lifetime, and he had also postulated another 'vital gas' in the heart and blood. At the same time Lower and Willis were investigating the difference in colour between venous and arterial blood (1658) and in 1665 Lower recognised that the blood was impregnated with nitrous particles from the air, in the lungs. John Mayo in 1674 showed that animals absorbed a quarter of the volume of the air in a bell-jar before they suffocated. Between 1755 and 1775 many gases were isolated and described, culminating in the latter year with oxygen, isolated independently by Schele, by Lavoisier (who saw that it demolished the phlogiston theory, which had held up progress for so long), and by Priestley, who also showed that if a mouse were suffocated in an enclosed volume of air, the same air would cause mint to grow phenomenally well, and that the mint 'restored' the air, so that it would keep a mouse alive again. This in itself separated 'Nitro-aerial particles' into two gases, explained the purpose of respiration, and what the circulation was for, underlining the fact that it is circulating blood, rather than the beating heart, which is essential to life.

All this came at a critical moment, when, just before the French Revolution, the new medicine of named diseases of organs, diagnosable during life, and confirmable by post-mortem examination after death, was being developed. The whole situation led at once to the examination of living patients by Corvisart and Desault, starting with Auenbrugger's method of percussion and culminating in the discovery by Corvisart's pupil Laënnec of mediate auscultation; and the relevance of Harvey's discovery at last became central to the whole of physiology and medicine, and not long afterwards to surgery. Harvey's discovery itself, and the scientific process by which it was made, have been the fount and origin of the medicine we know today.

Requests for reprints to Dr Charles Newman, Royal College of Physicians, 11 St. Andrew's Place, Regents Park, London NW1 4LE. 